\title{
Evidence of perceived psychosocial stress as a risk factor for stroke in adults: a meta-analysis
}

\author{
Joanne Booth ${ }^{1 *}$, Lesley Connelly ${ }^{1}$, Maggie Lawrence ${ }^{1}$, Campbell Chalmers ${ }^{2}$, Sara Joice ${ }^{3}$, Clarissa Becker ${ }^{1}$ \\ and Nadine Dougall ${ }^{4}$
}

\begin{abstract}
Background : Several studies suggest that perceived psychosocial stress is associated with increased risk of stroke; however results are inconsistent with regard to definitions and measurement of perceived stress, features of individual study design, study conduct and conclusions drawn and no meta-analysis has yet been published. We performed a systematic review and meta-analysis of studies assessing association between perceived psychosocial stress and risk of stroke in adults. The results of the meta-analysis are presented.

Methods: Systematic searches of MEDLINE, EMBASE, CINAHL, PsycInfo, and Cochrane Database of Systematic Reviews were undertaken between 1980 and June 2014. Data extraction and quality appraisal was performed by two independent reviewers. Hazard ratios (HR) and odds ratios (OR) were pooled where appropriate.

Results: 14 studies were included in the meta-analysis, 10 prospective cohort, 4 case-control design. Overall pooled adjusted effect estimate for risk of total stroke in subjects exposed to general or work stress or to stressful life events was 1.33 (95\% confidence interval $[\mathrm{Cl}], 1.17,1.50 ; P<0.00001$ ). Sub-group analyses showed perceived psychosocial stress to be associated with increased risk of fatal stroke (HR $1.4595 \% \mathrm{Cl}, 1.19,1.78 ; P=0.0002$ ), total ischaemic stroke (HR $1.4095 \% \mathrm{Cl}, 1.00,1.97 ; P=0.05)$ and total haemorrhagic stroke (HR $1.7395 \% \mathrm{Cl}, 1.33,2.25$; $P>0.0001$ ).A sex difference was noted with higher stroke risk identified for women (HR $1.9095 \% \mathrm{Cl}, 1.4,2.56$ : $P<0.0001)$ compared to men ( $\mathrm{HR} 1.2495 \% \mathrm{Cl}, 1.12,1.36 ; P<0.0001)$.
\end{abstract}

Conclusions: Current evidence indicates that perceived psychosocial stress is independently associated with increased risk of stroke.

Keywords: Stress, Psychological, Stroke, Risk factor

\section{Background}

There is a lack of attention paid to the potential role of psychosocial risk factors, including perceived psychosocial stress, in the development of stroke [1, 2]. The association between psychosocial stress and the development of coronary heart disease is strong [3-5]. A recently published overview of systematic reviews confirms modest to moderate evidence of the association between psychosocial stress at work and cardiovascular outcomes [6]. Research is less conclusive in the area of stroke, yet public perception highlights psychosocial stress as a key risk factor for stroke [7-9]. Several observational studies have identified

\footnotetext{
* Correspondence: jo.booth@gcu.ac.uk

'Institute for Applied Health Research, School of Health \& Life Sciences, Glasgow Caledonian University, Glasgow, Glasgow Caledonian University, Cowcaddens Road, Glasgow G4 OBA, UK

Full list of author information is available at the end of the article
}

an association between perceived psychosocial stress and stroke, [10-13] however conflicting findings have been reported and inconsistencies are apparent with respect to definition and measurement of perceived psychosocial stress, study design and quality, duration of follow-up and number of covariates adjusted for. This variability has resulted in different, and sometimes contradictory, conclusions being drawn about the relationship between perceived psychosocial stress and stroke [14-16]. There is no clarity of clinical message about any possible contribution of perceived psychosocial stress to stroke risk and a lack of evidence around the potential for stress modification interventions for primary or secondary prevention of stroke [17]. To date, no systematic review or meta-analysis of studies reporting associations between perceived psychosocial stress and stroke 
has been published. Psychosocial stressors, caused by relationship, occupational or financial-related stimuli, are recognised as potential contributors to an individual's perceptions of stress, which is the human response to exposure to psychosocial stressors and inability to cope with the demands made [18, 19]. However psychosocial stressors are under-investigated compared to more established biological and pathophysiological risk factors for stroke [17] and the complexity of the relationship between exposure to psychosocial stressors and perception of psychosocial stress is not fully understood. Studies have reported various sub-components of psychosocial stress, including self-perceived stress [12, 14-16] stressful life events (SLE) $[11,13]$ and poor adaptation to stress $[10]$ to be associated with an increased risk of stroke. We performed a systematic review and meta-analysis to evaluate the association between perceived psychosocial stress and stroke, and to clarify differential risks associated with types of stroke and sub-components of perceived stress. Stress as a trigger for stroke events was not included as this was not considered a component of risk. This paper reports the results of the meta-analysis.

\section{Methods}

The meta-analysis was undertaken according to the proposal for reporting Meta-analyses Of Observational Studies in Epidemiology (MOOSE) [20].

\section{Search strategy}

Systematic searches of published papers indexed in MEDLINE, EMBASE, CINAHL, PsycInfo and Cochrane Database of Systematic Reviews between 1980 and June 2014 were undertaken using a strategy combining selected subject headings and keywords relating to perceived psychosocial stress and stroke. The search strategy was developed for use in Medline (Fig. 1) and amended for use in other databases. Manual searching of reference lists and relevant systematic reviews and guidelines, was also performed. Results were filtered for English language.

\section{Study selection}

Studies were included in the meta-analysis if they met the following criteria: (1) prospective cohort or casecontrol design (2) self-reported exposure to SLE or selfreported perceived psychosocial stress or self-reported work stress or self-reported exposure to high strain work (3) use of adjusted models or matching procedures that controlled for potential confounders (4) reported risk estimates for stroke outcomes with $95 \%$ CI comparing participants who had experienced perceived psychosocial stress to participants who had not experienced perceived psychosocial stress or who had experienced perceived psychosocial stress to a lesser degree. Studies reporting a clinical diagnosis of depression or clinical diagnosis of anxiety were excluded, as were studies involving the composite construct of psychological distress unless a measure of perceived psychosocial stress could be extracted. In the case of overlapping data within and between studies, the report with the longest follow-up or largest number of participants was included. Studies were included in the meta-analysis if they reported risk estimates adjusted for at least three stroke risk factors. A broad definition of stroke was adopted, to include ischaemic stroke, haemorrhagic stroke, subarachnoid haemorrhage and TIA [21]. The definition of perceived psychosocial stress used was 'the self-reported sensation of tension, irritability, nervousness, anxiety or sleeplessness [12] associated with poor health, family relationships, living arrangements, finance, work and stressful life events'. Eligible studies were selected by a two stage process. Using the broad criteria of stroke and stress, two reviewers (from JB, LC, ML) independently screened titles and abstracts, where available, of bibliographic records retrieved. Full-text copies of potentially relevant studies were retrieved. Two reviewers then used the pre-determined selection criteria to assess eligibility. Disagreement was resolved by discussion with a third reviewer.

\section{Data extraction and quality appraisal}

Two reviewers extracted data independently (from JB, LC, ML, CC, SJ, CB) using a review-specific extraction tool. Data to be extracted included details of study design and methods; study populations including sex and age; types of stress exposure and method of measurement; stroke outcomes and measurement or confirmation method; number and type of confounders adjusted for and sensitivity analyses. Extracted data were cross-checked and disagreements resolved by consensus. Where indicated, authors were contacted and asked to provide missing information. Independent assessment of methodological quality was conducted using the Newcastle-Ottawa Quality Assessment Scales for Cohort Studies and Case-control Studies [22] to grade selection of participants, assessment of exposures and outcomes, and comparability and control of confounding. The maximum total score is 9 .

\section{Data synthesis}

For studies which reported adjusted risk estimates, a meta-analysis was performed to pool estimates of association. For cohort studies, hazard ratios (HRs) were used as the common risk estimate across studies (relative risks were considered equivalent to HRs). For case-control studies, odds ratios (ORs) were used as the common risk estimate. If different adjusted risk estimates were reported, the most fully adjusted estimate was included. Forest plots were produced to visually assess the 


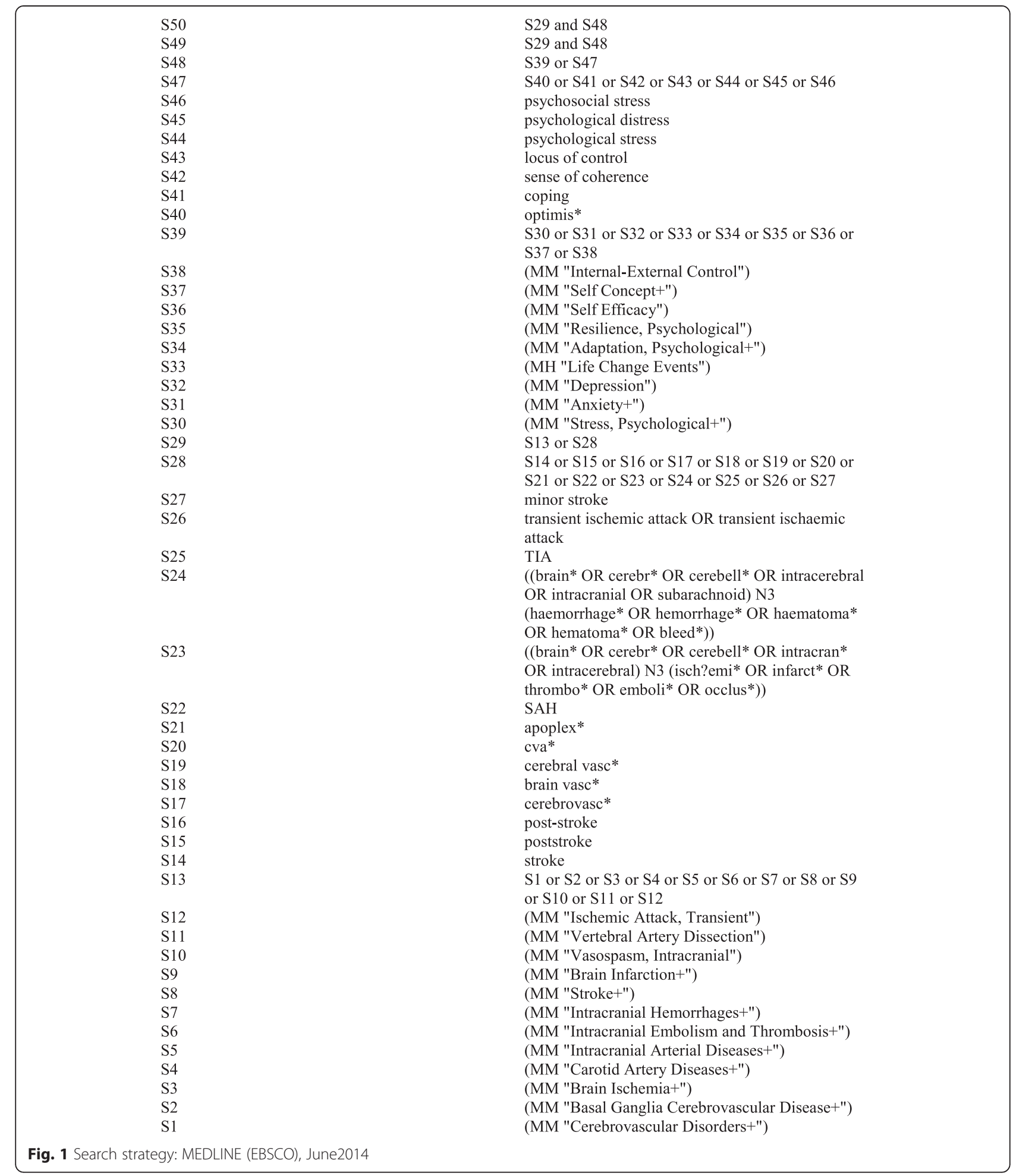

association across the included studies and the corresponding $95 \% \mathrm{CI}$. The chi-squared test was employed to determine strength of evidence that heterogeneity was genuine, where $P<.10$ was considered indicative of statistically significant heterogeneity. The $\mathrm{I}^{2}$ statistic was used to quantify inconsistency, the percentage variability in effect estimates due to heterogeneity between studies rather than sampling error within studies. An $\mathrm{I}^{2}$ value over $50 \%$ may indicate substantial heterogeneity. Pooled results were estimated using a random-effects model as 
this provides a more conservative estimate of exposure effect where there is a high likelihood of substantial between-study variance (DerSimonian and Laird model) [23]. Possibility of publication bias was evaluated by visual inspection for possible skewness in a funnel plot, and Egger regression [39] was used to judge the degree of publication bias. Sub-group analyses were undertaken for gender, type of stress exposure and type of stroke. Sensitivity analyses were performed to analyse influences of specific study characteristics. Analyses were performed using Review Manager Version 5.2 [24].

\section{Results}

\section{Literature search}

The search strategy identified 3775 citations, of which 14 were included in the meta-analysis, 10 prospective cohort studies (145,546 participants, 5725 stroke outcomes) and 4 case-control studies (4405 stroke cases, 4987 controls) (Fig. 2). In total 10,130 stroke outcomes from 154,938 participants were included in the meta-analysis.

\section{Study characteristics}

Characteristics of the studies are shown in Table 1 (cohort) $[2,3,14,25-28,30,31,33]$ and Table 2 (case control) $[15,16,29,32]$. Two prospective cohort studies reported results separately by sex with no risk estimate reported for the combined male and female cohort [3, 25]. Of 8 studies reporting results for a total sample of men and women, 2 studies $[15,28]$ provided stratified results by sex. The studies were undertaken across the full adult age range with 8 cohort studies reporting results for adults aged 40 and over [2, 3, 26-28, 30,31,33], 1 for adults aged 18 and over [25] and 1 for those aged 20 and over [14]. Three of the 4 case control studies included adults aged 18 and over $[15,16,29]$ and the eligible age for the fourth was 39. Characteristics of the stress exposure are shown in Tables 1 and 2. Thirteen studies measured stress exposures through self-report questionnaires, 1 study used a structured interview schedule [2]. The majority used study specific questionnaires but provided no information regarding validity or reliability. Five studies used validated tools $[25,26,29,31,32]$. Two studies looking at general stress used a single item questionnaire however no information was reported regarding its validity or reliability as a means of measuring stress $[15,16]$.

All studies confirmed stroke by death certificates, medical records, official registers or CT/MRI scan. Baseline stroke was not excluded in 4 studies [2, 15, 26, 27]; however a stratified analysis excluding these studies was undertaken. Stress exposure was measured once at baseline in 13 studies. McLeod et al. [26] performed a second screening 5 years post baseline. All risk estimates were adjusted for age, smoking status, BMI, and hypertension. The majority adjusted for physical activity [3, 14, 25-28, 30, 31, 33] (9 studies), diabetes $[2,3,14,25,27,30,33]$ (7 studies), alcohol consumption [3, 14, 25-28] (6 studies) and cholesterol $[25,26,28,30,31,33]$ (6 studies). In addition to traditional biological and lifestyle factors associated with stroke, all except one study [3] adjusted for social factors such as educational attainment, occupational status or social class, whilst 2 studies [3, 30] adjusted for depression or psychological factors other than stress. All cohort studies were of high methodological quality, scoring 7 or above (of a maximum possible 9) on the Newcastle Ottawa Quality Assessment Scale. Case control studies were less robust, scoring 5-7 of the possible maximum of 9 on the Newcastle Ottawa Quality Assessment Scale.

\section{Stress as a risk factor for stroke}

The overall pooled adjusted effect estimate for risk of total stroke in subjects exposed to general or work stress or to SLE versus control was 1.33 (95\% CI, 1.17, $1.50 ; P<0.00001)$ with substantial statistical heterogeneity $\left(\mathrm{I}^{2}=82 \%\right.$; $\mathrm{p}$ value for $\mathrm{Q}$ test $\left.<0.00001\right)$. The pooled HR for the 10 prospective cohort studies was 1.25 (95 \% CI 1.12, 1.39; $P<0.0001)$ with moderate statistical heterogeneity $\left(\mathrm{I}^{2}=43 \%\right.$; $\mathrm{p}$ value for $\mathrm{Q}$ test $\left.=0.06\right)$ and the pooled OR for the 4 case-control studies was 1.74 (95 \% CI 1.18, 2.55; $P=0.005)$ with considerable statistical heterogeneity $\left(\mathrm{I}^{2}=93 \%\right.$; $\mathrm{p}$ value for $\mathrm{Q}$ test $\left.<0.00001\right)$. Comparison between prospective cohort and case control studies revealed no significant difference $(P=0.11)$, indicating minimal methodological heterogeneity (Fig. 3).

\section{Subgroup analysis}

Results by sex were available from 10 prospective cohort studies. For men, 6 of 7 reported associations were positive with a pooled HR of 1.24 (95 \% CI, 1.12-1.36; $P<0.0001$ ). Three studies reporting women only results showed positive associations and a pooled HR of 1.90 (95 \% CI 1.40, $2.56 ; P<0.0001)$. One case control study reported no difference between sexes [15]. The different types of stress were considered separately and for the purposes of analysis were categorised as general stress, work stress and stressful life events. In the 7 prospective cohort studies that reported it, the pooled HR for general stress was 1.25 (95 \% CI, 1.091.42; $P=0.0009$ ), for work stress 1.39 (95 \% CI, 0.93, 2.10; $P=0.11$ ), and for stressful life events 1.32 (95\% CI, 0.77 , 2.26; $P=0.31$ ). In the 2 case control studies that reported general stress the pooled OR was 2.06 (95\% CI, 0.78-5.41; $P=0.14)$, and for stressful life events it was 1.88 (95\% CI, $0.51-6.93 ; P=0.34$ ). No case control studies relating to work stress were eligible for inclusion in the meta-analysis.

When considering the outcomes, six cohort studies reported results for fatal stroke with a pooled HR of 1.45 


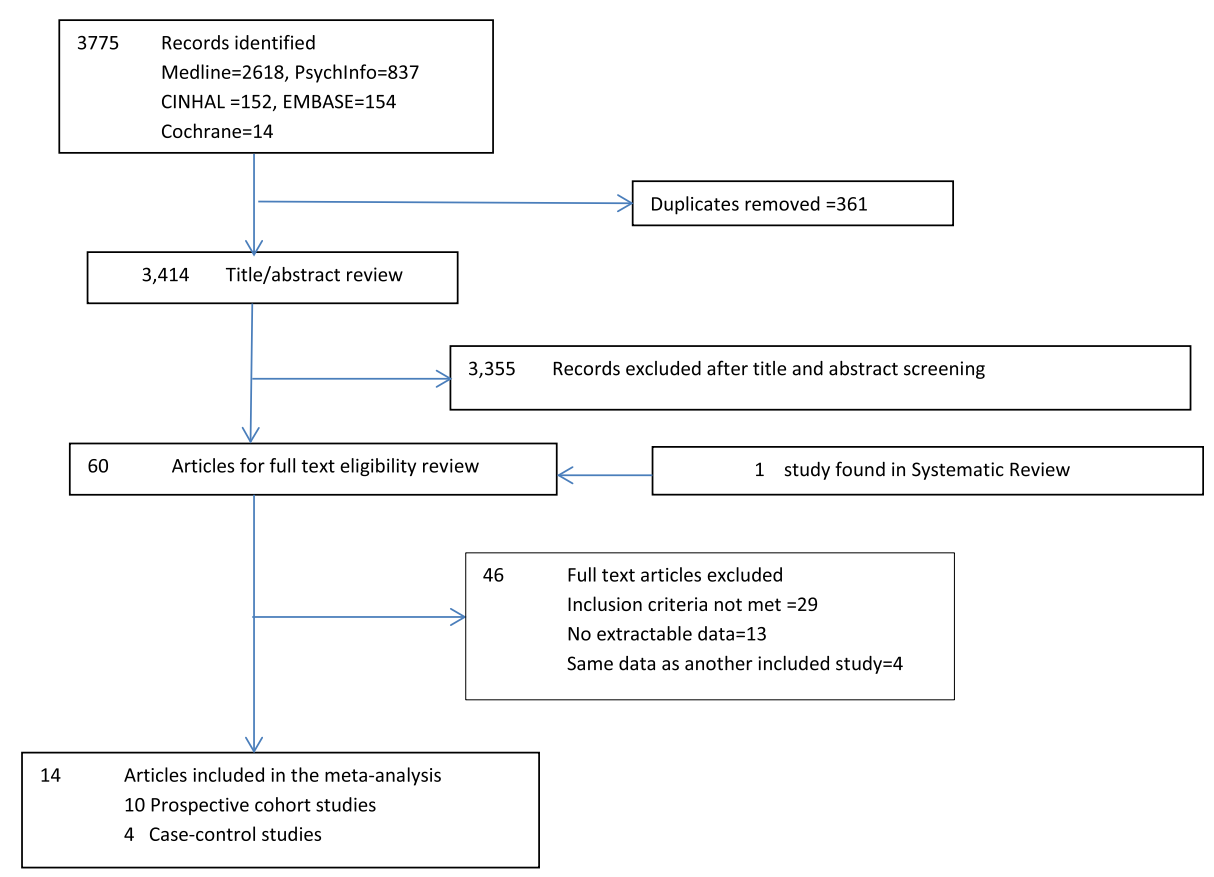

Fig. 2 Study selection flow chart

(95 \% CI, 1.19-1.78; $P=0.0002$ ). Two studies reported results for non-fatal stroke with a pooled HR of 0.98 (95\% CI, 0.89-1.08). When the type of stroke was considered the pooled HR for fatal and non-fatal ischaemic stroke was 1.40 (95\% CI, 1.00-1.97; $P=0.05$ ), and for fatal and non-fatal haemorrhagic stroke it was 1.73 (95 \% CI, 1.33-2.25; $P<0.0001$ ). In the case control studies the pooled OR for non-fatal ischaemic stroke in the 2 studies reporting results was 2.06 (95\% CI, 0.78$5.41 ; P=0.14)$. Only one case control study reported on haemorrhagic stroke separately [15] with an OR of 1.23 (99\% CI, 0.89-1.69).

\section{Sensitivity analysis}

Excluding the cohort study with the largest influence [3] and the cohort studies which did not exclude participants with baseline stroke [2, 26, 27] produced a similar pooled HR which remained statistically significant. Sensitivity analyses which excluded studies with less than 5000 participants $[27,31]$ or with less than 10 years follow-up [3, 30, 31] or those which did not control for diabetes $[26,28,31]$ also produced similar pooled HRs, which remained statistically significant. Excluding the case control study with the largest influence [16] changed the result from statistically significant to nonsignificant (OR $2.3095 \% \mathrm{CI}, 0.82-6.44 ; P=0.11$ ), as did excluding the case control study which did not exclude participants with baseline stroke [15] (OR $1.3795 \% \mathrm{CI}$, $0.98-1.92 ; P=0.07$ ). Analysis excluding the study with less than 500 cases [29] reduced the pooled OR to 1.46
(95 \% CI, 1.01-2.10; $P=0.04$ ) however it remained statistically significant.

\section{Publication bias}

The funnel plot appeared asymmetric, a number of the smaller studies estimated larger hazard ratios than the larger studies, and there was evidence of possible publication bias using the Egger method $(p=0.000)$ [39].

\section{Discussion}

Meta-analysis of 14 studies (10 cohort, 4 case-control) involving a total of 10,130 strokes found a positive association between perceived psychosocial stress and risk of stroke in adult men and women, suggesting that perceived psychosocial stress may be an independent risk factor for stroke. The combined pooled adjusted effect estimate showed a $33 \%$ increased risk of incident stroke in those reporting perceptions of psychosocial stress and was statistically significant in the separate cohort and case-control study analyses. The increased risk is moderate, being of similar magnitude to risk associated with diabetes mellitus, dietary risk score or depression [16] when compared to the larger effect size associated with history of hypertension, current smoking, waist-to-hip ratio, alcohol intake, regular physical activity, cardiac causes and ratio of apolipoproteins B to A1. Psychosocial stress is an imprecise term which has multiple interpretations. There is no accepted, universal definition and, depending on perspective, subjective stress comprises physiological, emotional, motivational and cognitive 
Table 1 Characteristics of included cohort studies

\begin{tabular}{|c|c|c|c|c|c|c|c|c|}
\hline \multirow{2}{*}{$\begin{array}{l}\text { Author Year } \\
\text { Country }\end{array}$} & \multirow[t]{2}{*}{ Quality rating } & \multirow{2}{*}{$\begin{array}{l}\text { Cohort size }(n) \\
\text { Baseline age range (y) }\end{array}$} & \multirow[t]{2}{*}{$\%$ Male } & \multirow{2}{*}{$\begin{array}{l}\text { Stroke cases ( } n) \\
\text { Follow-up years (y) }\end{array}$} & \multirow[t]{2}{*}{ Stress exposure and measure } & \multirow{2}{*}{$\begin{array}{l}\text { Stroke outcomes } \\
\text { Risk estimates Hazard } \\
\text { Ratio }(95 \% \mathrm{Cl})\end{array}$} & \multirow{2}{*}{$\begin{array}{l}\text { Baseline stroke } \\
\text { excluded }\end{array}$} & \multirow{2}{*}{$\begin{array}{l}\text { Number of confounders } \\
\text { controlled for in adjusted } \\
\text { model }\end{array}$} \\
\hline & & & & & & & & \\
\hline \multirow[t]{2}{*}{$\begin{array}{l}\text { Harmsen, } 2006 \text { [33] } \\
\text { Sweden }\end{array}$} & 8 & 7457 & 100 & 1019 & $\begin{array}{l}\text { Self-perceived stress } \\
\text { General stress }\end{array}$ & $\begin{array}{l}\text { Fatal and non-fatal } \\
\text { stroke }\end{array}$ & Yes & 11 \\
\hline & & $47-55$ & & 28.0 & Single question & $\begin{array}{l}1.25 \\
(1.03-1.52)\end{array}$ & & \\
\hline \multirow[t]{2}{*}{$\begin{array}{l}\text { Henderson, } 2013 \\
\text { [31] USA }\end{array}$} & 8 & 2326 & 38 & 414 & $\begin{array}{l}\text { Perceived stress } \\
\text { General stress }\end{array}$ & $\begin{array}{l}\text { Fatal and non-fatal } \\
\text { stroke }\end{array}$ & Yes & 10 \\
\hline & & $>=65$ & & 6.0 & $\begin{array}{l}6 \text { item perceived stress } \\
\text { scale }[41]\end{array}$ & $\begin{array}{l}1.08 \\
(0.97-1.20)\end{array}$ & & \\
\hline \multirow[t]{2}{*}{$\begin{array}{l}\text { Iso, } 2002[3] \text { Japan, } \\
\text { males }\end{array}$} & 8 & 30,180 & 100 & 341 & $\begin{array}{l}\text { Perceived mental stress } \\
\text { General stress }\end{array}$ & Fatal stroke & Yes & 9 \\
\hline & & $40-79$ & & 7.9 & Single question & $\begin{array}{l}1.12 \\
(0.78-1.61)\end{array}$ & & \\
\hline \multirow[t]{2}{*}{$\begin{array}{l}\text { Iso, } 2002[3] \text { Japan, } \\
\text { females }\end{array}$} & 8 & 43,244 & 0 & 316 & $\begin{array}{l}\text { Perceived mental stress } \\
\text { General stress }\end{array}$ & Fatal stroke & Yes & 9 \\
\hline & & $40-79$ & & 7.9 & Single question & $\begin{array}{l}2.24 \\
(1.52-3.30)\end{array}$ & & \\
\hline \multirow[t]{3}{*}{$\begin{array}{l}\text { Kornerup, } 2010 \text { [30] } \\
\text { Denmark }\end{array}$} & 8 & 9542 & 43 & 350 & $\begin{array}{l}>4 \text { major life events in a } \\
\text { life course }\end{array}$ & $\begin{array}{l}\text { Fatal and non-fatal } \\
\text { ischaemic stroke }\end{array}$ & Yes & 11 \\
\hline & & Mean M & & $6-9$ & SLE & & & \\
\hline & & $\begin{array}{l}56.6 \text { (SD 15.5) F-59.1 (SD } \\
15.4)\end{array}$ & & & 11 item self-report questionnaire & $\begin{array}{l}1.32 \\
(0.77-2.26)\end{array}$ & & \\
\hline \multirow[t]{2}{*}{$\begin{array}{l}\text { McLeod, } 2001[26] \\
\text { Scotland }\end{array}$} & 7 & 5388 & 100 & 122 & $\begin{array}{l}\text { Perceived stress } \\
\text { General stress }\end{array}$ & Fatal stroke & No & 9 \\
\hline & & $35-64$ & & 21.0 & $\begin{array}{l}4 \text { item Reeder stress inventory } \\
\text { [42] }\end{array}$ & $\begin{array}{l}0.98 \\
(0.55-1.75)\end{array}$ & & \\
\hline \multirow[t]{2}{*}{$\begin{array}{l}\text { Molshatzki, } 2013 \text { [2] } \\
\text { Israel }\end{array}$} & 7 & 10,059 & 100 & 665 & $\begin{array}{l}\text { Perceived hardships } \\
\text { General stress }\end{array}$ & Fatal stroke & No & 7 \\
\hline & & $>=40$ & & 28.1 & $\begin{array}{l}14 \text { questions on } \\
\text { work, family, finance }\end{array}$ & $\begin{array}{l}1.33 \\
(1.07-1.65)\end{array}$ & & \\
\hline \multirow[t]{2}{*}{$\begin{array}{l}\text { Ohlin, } 2004[28] \\
\text { Sweden }\end{array}$} & 8 & 13,280 & 80 & 643 & $\begin{array}{l}\text { Permanent stress } \\
\text { General stress }\end{array}$ & $\begin{array}{l}\text { Fatal and non-fatal } \\
\text { stroke }\end{array}$ & Yes & 9 \\
\hline & & Mean 45 & & 21.3 & 2 questions & $\begin{array}{l}1.29 \\
(1.04-1.60)\end{array}$ & & \\
\hline \multirow[t]{3}{*}{$\begin{array}{l}\text { Suadicani, } 2011 \text { [27] } \\
\text { Denmark }\end{array}$} & 7 & 4943 & 100 & 779 & $\begin{array}{l}\text { Perceived psychological work } \\
\text { pressure }\end{array}$ & $\begin{array}{l}\text { Fatal and non-fatal } \\
\text { stroke (excl SAH) }\end{array}$ & No & 8 \\
\hline & & $40-59$ & & 30.0 & Leisure stress & 1.17 & & \\
\hline & & & & & 3 questions & (C) & & \\
\hline
\end{tabular}


Table 1 Characteristics of included cohort studies (Continued)

\begin{tabular}{|c|c|c|c|c|c|c|c|c|}
\hline \multirow[t]{2}{*}{$\begin{array}{l}\text { Truelsen, } 2003 \text { [14] } \\
\text { Denmark }\end{array}$} & \multirow[t]{2}{*}{8} & 12,574 & \multirow[t]{2}{*}{45} & 929 & $\begin{array}{l}\text { Self-reported stress } \\
\text { General stress }\end{array}$ & $\begin{array}{l}\text { Fatal and non-fatal } \\
\text { stroke }\end{array}$ & \multirow[t]{2}{*}{ Yes } & \multirow[t]{2}{*}{11} \\
\hline & & $20-98$ & & $14-16$ & 2 questions & $\begin{array}{l}1.13 \\
(0.85-1.50)\end{array}$ & & \\
\hline \multirow[t]{2}{*}{$\begin{array}{l}\text { Tsutsumi, } 2009[25] \\
\text { Japan Males }\end{array}$} & \multirow[t]{2}{*}{8} & 3190 & \multirow[t]{2}{*}{100} & 91 & Occupational stress & $\begin{array}{l}\text { Fatal \& Non-fatal } \\
\text { stroke }\end{array}$ & \multirow[t]{2}{*}{ Yes } & \multirow[t]{2}{*}{10} \\
\hline & & $18-65$ & & 11.0 & $\begin{array}{l}11 \text { item demand-control } \\
\text { questionnaire }\end{array}$ & $\begin{array}{l}2.53 \\
(1.08-5.93)\end{array}$ & & \\
\hline \multirow[t]{2}{*}{$\begin{array}{l}\text { Tsutsumi, } 2009 \text { [25] } \\
\text { females }\end{array}$} & \multirow[t]{2}{*}{8} & 3363 & \multirow[t]{2}{*}{0} & 56 & Occupational stress & $\begin{array}{l}\text { Fatal \& Non-fatal } \\
\text { stroke }\end{array}$ & \multirow[t]{2}{*}{ Yes } & \multirow[t]{2}{*}{10} \\
\hline & & $18-65$ & & 11.0 & $\begin{array}{l}11 \text { item demand-control } \\
\text { questionnaire }\end{array}$ & $\begin{array}{l}1.46 \\
(0.63-3.38)\end{array}$ & & \\
\hline
\end{tabular}


Table 2 Characteristics of included case-control studies

\begin{tabular}{|c|c|c|c|c|c|c|c|c|}
\hline \multirow{2}{*}{$\begin{array}{l}\text { Author Year } \\
\text { Country }\end{array}$} & \multirow[t]{2}{*}{ Quality rating } & \multirow{2}{*}{$\begin{array}{l}\text { Cases: controls } \\
\text { Type of controls } \\
\text { Age range }(y)\end{array}$} & \multirow[t]{2}{*}{$\%$ Male } & \multirow{2}{*}{$\begin{array}{l}\text { Cases: controls with } \\
\text { stress }\end{array}$} & \multirow[t]{2}{*}{ Stress exposure and measure } & \multirow{2}{*}{$\begin{array}{l}\text { Stroke outcomes } \\
\text { Risk estimates Odds } \\
\text { Ratio }(95 \% \mathrm{Cl}) \\
\end{array}$} & \multirow{2}{*}{$\begin{array}{l}\text { Previous stroke } \\
\text { excluded }\end{array}$} & \multirow{2}{*}{$\begin{array}{l}\text { Number of confounders } \\
\text { controlled for in fully } \\
\text { adjusted model }\end{array}$} \\
\hline & & & & & & & & \\
\hline \multirow[t]{2}{*}{$\begin{array}{l}\text { Jood, } 2009 \text { [15] } \\
\text { Sweden }\end{array}$} & \multirow[t]{2}{*}{7} & \multirow[t]{2}{*}{$\begin{array}{l}600: 600 \\
\text { Population } \\
18-69\end{array}$} & \multirow[t]{2}{*}{64} & \multirow[t]{2}{*}{$126: 46$} & $\begin{array}{l}\text { Permanent self-perceived } \\
\text { psychological stress } \\
\text { General stress }\end{array}$ & $\begin{array}{l}\text { Non-fatal ischaemic } \\
\text { Stroke }\end{array}$ & \multirow[t]{2}{*}{ No } & \multirow[t]{2}{*}{10} \\
\hline & & & & & Single question & $\begin{array}{l}3.49 \\
(2.06-5.91)\end{array}$ & & \\
\hline \multirow[t]{3}{*}{$\begin{array}{l}\text { O'Donnell } 2010 \text { [16] } \\
22 \text { countries }\end{array}$} & \multirow[t]{3}{*}{5} & $3000: 3000$ & \multirow[t]{3}{*}{63} & \multirow[t]{3}{*}{$589: 440$} & $\begin{array}{l}\text { Psycho-social stress } \\
\text { General stress }\end{array}$ & $\begin{array}{l}\text { Non-fatal stroke } \\
\text { (excludes SAH) }\end{array}$ & \multirow[t]{3}{*}{ Yes } & \multirow[t]{3}{*}{13} \\
\hline & & $\begin{array}{l}\text { Hospital or } \\
\text { community }\end{array}$ & & & \multirow[t]{2}{*}{ Single question } & \multirow[t]{2}{*}{$\begin{array}{l}1.30 \\
(1.11-1.52)\end{array}$} & & \\
\hline & & $\begin{array}{l}\text { Mean 61.1 } \\
(\mathrm{SD} 12.7)\end{array}$ & & & & & & \\
\hline \multirow[t]{5}{*}{ Abel, 1999 [32] USA } & \multirow[t]{5}{*}{5} & $655: 1087$ & \multirow{5}{*}{$\begin{array}{l}44.6 \% \text { cases, } \\
39.9 \% \text { controls }\end{array}$} & \multirow{5}{*}{$\begin{array}{l}\text { Categorical boundary for } \\
\text { stress risk factor not used } \\
\text { so raw numbers 'with } \\
\text { stress RF' not reported }\end{array}$} & \multirow{5}{*}{$\begin{array}{l}20 \text { point increase on GSRRS } 35 \\
\text { item Geriatric Social Readjustment } \\
\text { Rating Scale [43] } \\
\text { General stress }\end{array}$} & \multirow{3}{*}{$\begin{array}{l}\text { Fatal \& non-fatal } \\
\text { ischaemic stroke }\end{array}$} & \multirow[t]{5}{*}{ Yes } & \multirow[t]{5}{*}{7} \\
\hline & & Community & & & & & & \\
\hline & & Mean age & & & & & & \\
\hline & & Cases 69.8 & & & & \multirow{2}{*}{$\begin{array}{l}1.01 \\
(0.99-1.03)\end{array}$} & & \\
\hline & & Controls 70.2 & & & & & & \\
\hline \multirow{7}{*}{$\begin{array}{l}\text { Egido, } 2012 \text { [29] } \\
\text { Spain }\end{array}$} & \multirow[t]{7}{*}{6} & $150: 300$ & $77.3 \%$ cases, & $62: 50$ (41.4 \%:16.7 \%) & Score $>=150$ on Holmes $\&$ Rahe & Non-fatal stroke (90\% & Yes & 9 \\
\hline & & Population & & & events [41] & w & & \\
\hline & & Mean age & & & 8 item ERCTA (Recall & & & \\
\hline & & Cases 53.8 & & & scale of Iype & 3.84 & & \\
\hline & & (SD 9.3) & & & & & & \\
\hline & & Controls 53.6 & & & & & & \\
\hline & & (SD 9.6) & & & & & & \\
\hline
\end{tabular}




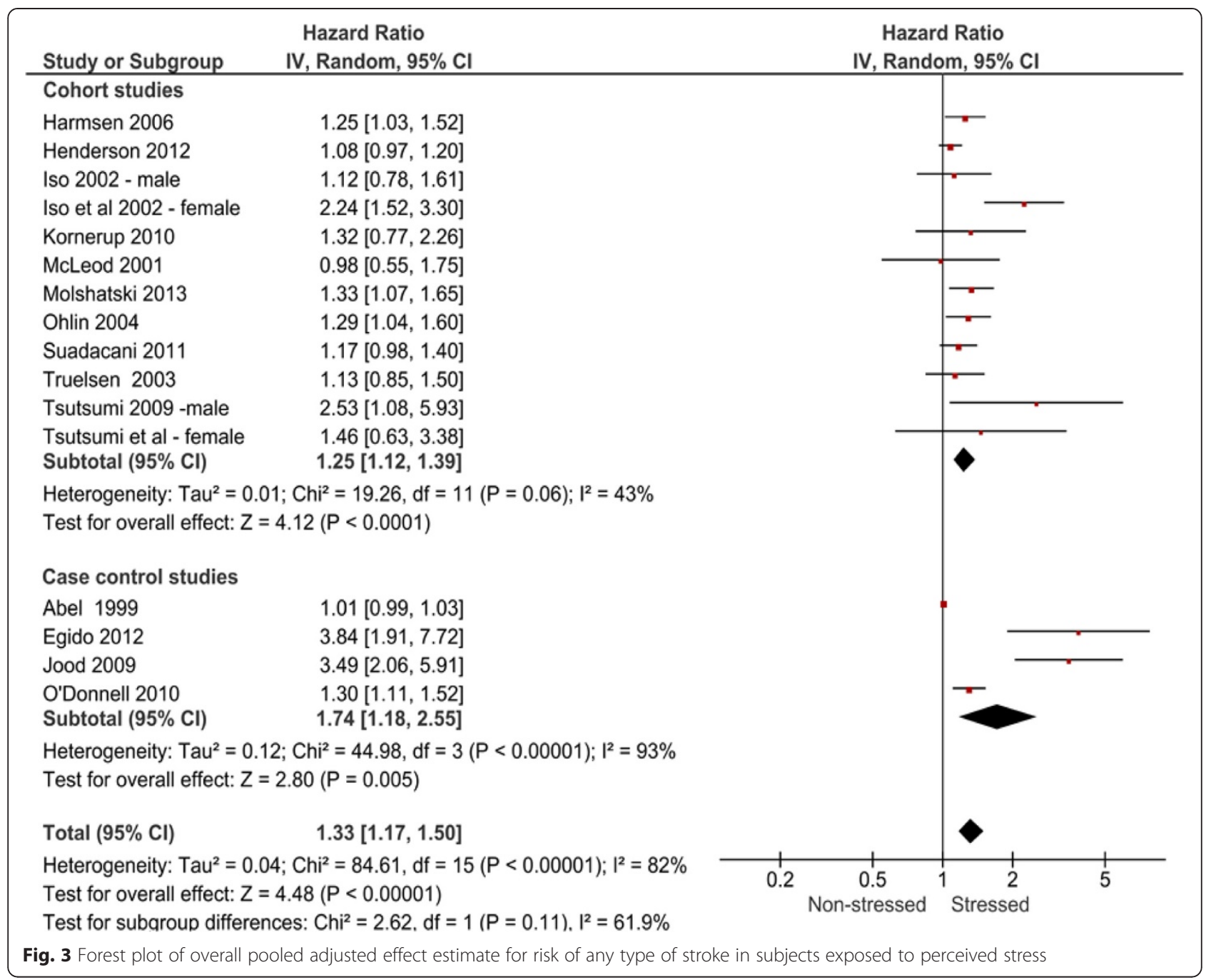

elements all of which may indicate a degree of stress response [35]. In this review we chose not to narrowly define type of psychosocial stress. An inclusive approach was taken involving wide-ranging descriptions of perceived stress such as general stress, where type of stress was not detailed, occupational stress and major life events [34]. However the common essential element was the report of subjective stress, as perceived and self-reported by study respondents, not stress that was objectively assessed or measured by another means. The concept of individual perception of stress was important in the absence of any measure or biomarker for actual stress level.

Nevertheless the validity of the exposure measurements of perceived psychosocial stress can be questioned. The majority of the studies included in the meta-analysis used study-specific questionnaires and for many this comprised a single question. The focus of this was broad ranging covering such areas as perceived stress at home or work and including different intensities of exposure from some periods to permanent stress. It is questionable how sensitive the different measures of perceived stress were and indeed their discriminatory properties. A feature to be considered is the extent to which socioeconomic disadvantage was identified, both previous and current, because a sensitive measure of this may explain the observed increase in stroke risk when material disadvantage and associated behavioural hazards are taken into account.

Subgroup analysis to identify specific type of perceived stress associated with stroke was inconclusive with only general stress showing a clear association with increased risk. In nine of the ten cohort studies and two of the four case-control studies general stress indicated perceptions of chronic stress, rather than the result of an individual stressful event or accumulation of stressful life events. These findings potentially resolve some contradictions in the published evidence regarding the type of perceived stress associated with risk of stroke, demonstrating that ongoing perceived stress of a continuous or 
regular nature was associated with increased risk of stroke. The relative lack of studies measuring discrete life events in this meta-analysis leaves unanswered the question of whether discrete life events contribute to stress-associated stroke risk.

The eligibility criterion of requiring self-report of psychosocial stress limited the studies that could be included in the meta-analysis. This applied to studies of occupational stress in particular where workplace exposure to psychosocial stress was often determined according to a previously developed Job Exposure Matrix of demand and control for a diverse range of occupations rather than self-reported answers to questions about perceived psychosocial stress [45]. Thus the risks associated with perceived work stress remain speculative.

Subgroup analysis also confirmed that perceived psychosocial stress was linked to stroke in both sexes however higher risk was associated with female sex. There is no clear explanation for this difference and it is not known whether this result indicates that women are exposed to higher levels of stress, whether female perceptions of psychosocial stress are different to male, or whether their reporting experiences of stress are different. Our results concur with those from a literature review of work-stress related stroke among working women, which suggested that work stress may be a more powerful predictor of stroke among women than men [46]. However female sex specific data are limited and these findings should be investigated further to identify potential explanatory mechanisms. With regard to type of stroke, analysis revealed a significant association between perceived psychosocial stress and fatal stroke of all types but this relationship was not identified in the non-fatal stroke data. Both ischaemic and haemorrhagic stroke were associated with perceived psychosocial stress; however the stronger association was with haemorrhagic stroke. These results contrast with a large individual-participant data meta-analysis of occupational job strain and risk of stroke which found work stress to be associated with a $20 \%$ increased risk of ischaemic stroke but no association with haemorrhagic stroke [47] and serves to highlight the need for a greater understanding of the biology underlying stress effects.

Potential mechanisms to explain the association by which psychosocial stress may increase risk of stroke are complex and not fully elucidated. Possible explanations relate to impact of perceived psychosocial stress on vascular inflammation, oxidative stress or immune dysfunction underpinning the basic pathophysiology of vascular disease [36]. Perceived stress is related to increased catecholamine release and sympathetic activation, which may either directly or indirectly affect the vascular system, eg increase thickening of the intima media, progression of carotid arterial disease and impact on blood pressure. Additionally, perceived stress adversely affects immune responses [37] which may result in increased susceptibility to complications of stroke and thus may contribute to explaining the association between perceived stress and fatal stroke in particular. It may also be the case that individuals with high perceived stress levels have more severe strokes although a mechanism for this has yet to be proposed. Additional to potential pathophysiological mechanisms, studies have also reported adverse behavioural risk profiles with regard to rates of smoking, physical activity and alcohol consumption in those who perceive themselves to be stressed [38]. The results of the meta-analysis indicating the association between perceived psychosocial stress and stroke, have potential clinical relevance suggesting interventions to manage or reduce perceived stress to be worthy of further investigation, with implications for secondary prevention of stroke. Despite the limited success of interventions to reduce psychosocial stress in primary and secondary prevention of cardiovascular disease [17], perceived psychosocial stress is theoretically modifiable. It is currently the subject of increased attention through a raised interest in interventions such as mindfulness based stress reduction [40].

\section{Limitations}

The main limitations relate to lack of an agreed definition of perceived psychosocial stress and its measurement, therefore variation and overlap in the perceived psychosocial stress reported may have occurred. As stress was self-reported there is no objectivity in stress measures used, thus understanding and interpretation of what was asked of each participant may vary. A number of studies measured psychosocial stress using a single question, which inevitably will encompass a spectrum of individual interpretations including sensations of anxiety and depression. It is acknowledged that these constructs are difficult to separate out from perceived psychosocial stress and should be considered, although the diagnosed clinical conditions were excluded from the review. Significant heterogeneity was found across the studies which may result from differences in perceived stress measures as well as differences in study design, sample sizes, strategies for analysis and participant characteristics. Several studies examined perceived stress in a younger patient population, where the stroke incidence rate was lower than in those studies with higher proportions of older adults and this may have affected the statistical power to observe significant results. Study selection was limited to English language only, which may have resulted in missing important insights and sample sizes in some studies were small. There was variation in followup periods, although none shorter than 6 years and many studies focused on middle-aged men with limited 
women-specific data, despite the indication that impact of perceived stress may be greater for this group. It was noted that measures of perceived stress in middle age might further be confounded by other previously accumulated adversity relevant to stroke risk. One potential limitation that should be considered is that perceived stress was reported at baseline, with a follow up of 6-30 years and it cannot be assumed that the level of perceived psychosocial stress reported at baseline was consistent or sustained prior to experiencing a stroke.

\section{Conclusion}

This meta-analysis demonstrates perceived psychosocial stress to be an independent risk factor for stroke, albeit of relatively modest magnitude. A number of hypotheses can be proposed to explain the association, however the first step is to demonstrate that a relationship exists, which this study achieves. The next steps will investigate potential moderators of the relationship, mediating mechanisms underpinning the association, and demonstration of causal links to explain the observed association.

\section{Competing interests}

The authors declare they have no competing interests.

\section{Authors' contributions}

$J B$ led the review process. $L C$ and $M L$ undertook the searches. JB, LC, ML, CC, $\mathrm{SJ}, \mathrm{CB}$ contributed to study selection and data extraction. JB, LC undertook the meta-analysis. Statistical support was provided by ND. JB, LC wrote the manuscript and all authors read and approved the final manuscript.

\section{Acknowledgements}

We acknowledge the helpful comments on the manuscript provided by Professor Martin Dennis, University of Edinburgh. The work was supported by a Queens Nursing Institute Scotland grant awarded to Professor Booth and Dr Lawrence: Reference number: EJPSS01.

\section{Author details}

${ }^{1}$ Institute for Applied Health Research, School of Health \& Life Sciences, Glasgow Caledonian University, Glasgow, Glasgow Caledonian University, Cowcaddens Road, Glasgow G4 OBA, UK. NHS Lanarkshire, Coathill Hospital, Hospital Street, Coatbridge ML5 4DN, UK. ${ }^{3}$ School of Psychology, Massey University, Private Bag 11 222, Palmerston North, New Zealand. ${ }^{4}$ Nursing, Midwifery \& Allied Health Professions Research Unit, University of Stirling Unit 13 Scion House, Stirling University Innovation Park, Stirling FK9 4NF, UK.

Received: 12 May 2015 Accepted: 2 October 2015

Published online: 12 November 2015

\section{References}

1. Feigin VL, Forouzanfar MH, Krishnamurthi R, Mensah G, Connor M, Bennett D, et al. Global and regional burden of stroke during 1990-2010: findings from the Global Burden of Disease Study 2010. Lancet. 2014;383:245-55.

2. Molshatzki N, Goldbourt U, Tanne D. Perceived hardships at midlife: Predication of long-term stroke mortality. Int J Cardiol. 2013;168:2278-81.

3. Iso H, Date C, Yamamoto A, Toyoshima H, Tanabe N, Kikuchi S, et al. Perceived mental stress and mortality from cardiovascular disease among Japanese men and women. Circulation. 2002;106:1229-36.

4. Stansfield SA, Fuhrer R, Shipley MJ, Marmott MG. Psychological distress as a risk factor for coronary heart disease in the Whitehall II study. Int J Epidemiol. 2002;31:248-55.

5. Rosengren A, Hawken S, Ounpuu S, Sliwa K, Zubaid M, Almahmeed W, et al. Association of psychosocial risk factors with risk of acute myocardial infarction in 11119 cases and 13648 controls from 52 countries (the INTERHEART study): case-control study. Lancet. 2004;364:953-62.
6. Fishta A, Backe E. Psychosocial stress at work and cardiovascular diseases an overview of systematic reviews. Int Arch Occup Environ Health. 2015. doi:10.1007/s00420-015-1019-0.

7. Muller-Nordhorn J, Nolte CH, Rossnagel K, Jungehulsing G, Reich A, Roll S, et al. Knowledge about risk factors for stroke: A population-based survey with 28090 participants. Stroke. 2006;37:946-50.

8. Pancioli AM, Broderick J, Kothari R, Brott T, Tuchfarber A, Miller T, et al. Public perception of stroke warning signs and knowledge of potential risk factors. JAMA. 1998;279:1288-92.

9. Yoon S, Heller R, Levi C, Wiggers J, Fitzgerald P. Knowledge of stroke risk factors, warning symptoms and treatment among an Australian urban population. Stroke. 2001;32:1926-30.

10. Surtees $P$, Wainwright $N$, Luben $R$, Wareham $N$, Bingham $S$, Khaw KT Adaptation to social adversity is associated with stroke incidence. Evidence from the EPIC-Norfolk Prospective Cohort Study. Stroke. 2007;38:1447-53.

11. House A, Dennis M, Mogridge L, Hawton K, Warlow C. Life events and difficulties preceding stroke.J Neurol. Neurosurg and Psych. 1990;53:1024-8.

12. Harmsen $P$, Rosengren A, Tsipogianni A, Wilhelmsen L. Risk factors for stroke in middle-aged men in Goteborg, Sweden. Stroke. 1990;21:223-9.

13. Engstrom G, Kahn F, Zia E, Jerntorp I, Pessah-Rasmussen H, Norrving B, et al. Marital dissolution is followed by and increased incidence of stroke. Cerebrovascular Diseases. 2004;18:318-24.

14. Truelsen T, Nielsen N, Boysen G, Gronbaek M. Self-reported stress and risk of stroke. The Copenhagen City Heart Study. Stroke. 2003;34:856-62.

15. Jood K, Redfors P, Rosengren A, Blomstrand C, Jern C. Self-perceived psychological stress and ischaemic stroke: a case-control study. BMC Medicine. 2009;7:53.

16. O'Donnell MJ, Xavier D, Liu L, Zhang H, Chin S, Rao-Melacini P, et al. Risk Factors for ischaemic and intracerebral haemorrhagic stroke in 22 countries (the INTERSTROKE study): a case control study. Lancet. 2010;376:112-23.

17. Tan M, Morgan K. Psychological interventions in cardiovascular disease: an update. Curr Opin Psychiatry. 2015;28:371-7.

18. Chida $Y$, Hamer M. An association of adverse psychosocial factors with diabetes mellitus: a meta-analytic review of longitudinal cohort studies. Diabetologia. 2008;51:2168-78.

19. Lazarus RS. From psychological stress to the emotions: a history of changing outlooks. Annu Rev Psychol. 1993;44:1-21.

20. Stroup DF, Berlin JA, Morton SC, Olkin I, Williamson G, Rennie D, et al. Metaanalysis of observational studies in epidemiology: a proposal for reporting. Meta-analysis Of Observational Studies in Epidemiology (MOOSE) group. JAMA. 2000;283:2008-12.

21. Hatano S. on behalf of the participants in the WHO Collaborative Study on the Control of Stroke in the Community. Experience from a multi-centre stroke register: a preliminary report. Bull World Health Org. 1976;54:541-53.

22. Wells GA, Brodsky L, O'Connell D, Peterson J, Welch V, Losos M et al. An Evaluation of the Newcastle-Ottawa Scale: An Assessment Tool for Evaluating the Quality of Non-Randomized Studies. In: XI International Cochrane Colloquium Book of Abstracts, Barcelona: Wiley-Blackwell; 2003: 26 http://www.ohri.ca/programs/clinical_epidemiology/nosgen.pdf

23. DerSimonian R, Laird N. Meta-analysis in clinical trials. Control Clin Trials. 1986;7:177-88.

24. Review Manager (RevMan) [Computer program]. Version 5.2. Copenhagen: The Nordic Cochrane Centre, The Cochrane Collaboration, 2012.

25. Tsutsumi A, Kayaba K, Kario K, Ishikawa S. Prospective study on occupational stress and risk of stroke. Arch Intern Med. 2009;169:56-61.

26. Macleod J, Davey Smith G, Heslop P, Metcalfe C, Carroll D, Hart C. Are the effects of psychosocial exposures attributable to confounding? Evidence from a prospective observational study on psychological stress and mortality. J Epidemiol Community Health. 2001;55:878-84.

27. Suadicani P, Andersen LL, Holtermann A, Mortensen OS, Gyntelberg F. Perceived psychological pressure at work, social class, and risk of stroke. A 30-year follow-up in Copenhagen male study. Journal of Occupational and Environmental Medicine. 2011;53:1388-95.

28. Ohlin B, Nilsson PM, Nilsson J-A, Berglund G. Chronic psychosocial stress predicts long-term cardiovascular morbidity and mortality in middle-aged men. European Heart Journal. 2004;25:867-73.

29. Egido JA, Castillo O, Roig B, Sanz I, Herrero M, Garay M, et al. Is psycho-physical stress a risk factor for Stroke? A case-control study. J Neurol Neurosurg Psychiatry. 2012;83:1104-10.

30. Kornerup H, Osler M, Boysen G, Barefoot J, Schnohr P, Prescott E. Major life events increase the risk of stroke but not of myocardial infarction: results 
from the Copenhagen City Heart Study. European Journal of Cardiovascular Prevention \& Rehabilitation. 2010;17:113-8.

31. Henderson KM, Clark CJ, Lewis TT, Aggarwal N, Beck T, Guo H, et al. Psychosocial distress and stroke risk in older adults. Stroke. 2013;44:367-72.

32. Abel GA, Chun X, Boden-Alballa B, Sacco RL. Social readjustment and ischemic stroke: Lack of an association in a multi-ethnic population. Neuroepidemiology. 1999;18:22-30

33. Harmsen P, Lappas G, Rosengren A, Wilhelmsen L. Long-Term Risk Factors for Stroke: Twenty-Eight Years of Follow-Up of 7457 Middle-Aged Men in Goteberg. Sweden Stroke. 2006;37:1663-7.

34. Yusuf S, Hawken S, Ounpuu S, Dans T, Avisum A, Lannas S, et al. On behalf of the INTERHEART study investigators. Effect of potentially modifiable risk factors associated with myocardial infarction in 52 countries (the INTERHEART study): case-control study. Lancet. 2004;372:224-33.

35. Matthews G, Deary IJ, Whiteman MC. Personality Traits. Stress. In: Matthews G, Deary IJ, Whiteman MC, editors. Personality Traits. 3rd ed. New York, NY: Cambridge University Press; 2009. p. 269-300.

36. Houston MC. New Concepts in the Diagnosis and Non-Surgical Treatment of Cardiovascular Disease. Intern Med S12: 003. doi:10.4172/2165-8048.S12-003

37. Walburn J, Vedhara K, Hankins M, Rixon L, Weinman J. Psychological stress and wound healing in humans: A systematic review and meta-analysis. Journal of Psychosomatic Research. 2009;67:253-71.

38. Dimsdale JE. Psychological stress and cardiovascular disease. J Am Coll Cardiol. 2008;51:1237-46.

39. Egger M, Smith GD, Schneider M, Minder C. Bias in meta-analysis detected by a simple, graphical test. BMJ. 1997;315:629-34.

40. Lawrence M, Booth J, Mercer S, Crawford E. A systematic review of the benefits of mindfulness-based interventions following transient ischemic attack and stroke. Int J Stroke. 2013;8:465-74.

41. Cohen S, Kamarck T, Mermelstein R. A global measure of perceived stress. $J$ Health Soc Behav. 1983;24:385-96.

42. Reeder LG, Chapman JM, Coulson AH. Socioenvironmental stress, tranquilizers and cardiovascular disease. Proceedings of the Excerpta Medica International Congress Series. 1968;182:226-38.

43. Holmes TS, Rahe RH. The social readjustment rating scale. J Psychosomatic Res. 1976;11:213e18.

44. Rodrıguez Sutil C, Gil Corbacho P, Martınez AR. Patron de conductatipo A, a traves de la escala ERCTA en sujetos normales y enfermos cardiovasculares. Clinica y salud. 1997;8:347e56

45. Toren K, Schioler L, Giang W, Novak M, Soderberg M, Rosengren A. A longitudinal general population-based study of job strain and risk for coronary heart disease and stroke in Swedish men. BMJ Open. 2014;4:e004355.

46. Toivanen S. Social determinants of stroke as related to stress at work among working women: A literature review. Stroke Research and Treatment 2012, article ID 873678 doi:10.1155/2012/873678

47. Fransson E, Nyberg S, Heikkila K, Alfredsson L, Bjorner J, Borritz M, et al. Job strain and the risk of stroke. An individual-participant data meta-analysis. Stroke. 2015;46:557-9.

\section{Submit your next manuscript to BioMed Central and take full advantage of:}

- Convenient online submission

- Thorough peer review

- No space constraints or color figure charges

- Immediate publication on acceptance

- Inclusion in PubMed, CAS, Scopus and Google Scholar

- Research which is freely available for redistribution 